\title{
Enhancement of Horticultural Crops for Improved Health
}

\author{
Henry M. Munger \\ Department of Plant Breeding, Cornell University, Ithaca, NY 14853
}

The dictionary gives several definitions of the word "enhance" that sound very similar but suggest different approaches to increasing the contribution of horticultural crops to improved human health. The first is "to exalt or to extol." In this sense, nutritionists recently have been recommending fruits and vegetables more strongly than ever for their benefits to human health. We read of the value of onions (Allium cepa L.) and related species in reducing heart disease, of cruciferous vegetables in reducing the risk of cancer, of the vitamins in numerous fruits and vegetables that correct vitamin deficiencies, of the value of vitamins and fiber in reducing both heart disease and cancer, and the greater value of vitamins from fruits and vegetables than from vitamin supplements. We are urged to include five servings of fruits and vegetables in our daily diets but read that many fall short of this goal, even in the United States with its abundant supplies.

Other words used in defining enhancement include "augmenting" or "making greater as in value or desirability." Among the subjects included in this colloquium is increasing the value of horticultural crops in delivering pharmaceuticals and micronutrients. Considerable effort has gone into breeding for higher nutrient levels in both horticultural and field crops for many decades, but this is not well known because there has been little usage of the resulting varieties. Gabelman (1974) pointed out that growers, handlers, and consumers all have criteria for choosing varieties, and difference in nutritional value does not have high ranking in their priorities. Lack of visibility also hinders recognition and use of more nutritious varieties. The importance of visibility is illustrated by the recent success of high-carotene carrots (Daucus carota L.), described by Philip Simon (1995). Many people commend today's carrots, but I have heard no consumer speak of their high vitamin A contribution as the reason for buying them. The improved color and flavor of the new hybrid carrots are certainly more important than nutritional value in causing a dramatic increase in their usage.

Perhaps desirability is the key word in the definition of enhancement as "making greater as in value or desirability." Stevens (1974) pointed out that crops with the highest rank for relative nutritional value tend to be ranked lowest for relative contribution to nutrition because they are not consumed in large quantities. Broccoli (Brassica oleracea L. Botrytis Group), brussels sprouts (B. oleracea L. Gemmifera Group), spinach (Spinacea oleracea L.), and lima beans (Phaseolus lunatus L.) were at the top of this list. Nearly a quarter-century later, this picture has changed, as broccoli has become one of the most important vegetables in the United States. It would be useful to know to what extent that change can be attributed to breeding, cultural methods, marketing, and consumer education. Whatever the reasons, increased consumption of broccoli has probably contributed more to improving nutrition than all efforts to increase the nutrient content of other crops, especially if we exclude the unique situation with carrots. The broccoli example is important because it shows that eating habits can be changed for the better. People younger than I can remember when broccoli was almost unknown as a vegetable. We need to give more attention to similar enhancement of other highly nutritious vegetables, some of which are grown mainly in the tropics and have received little attention from horticultural scientists.

Some of the lesser-known crops have the greatest potential for increasing the calorie and protein supply for the world's exploding population, while at the same time providing essential vitamins and minerals. With 1 billion persons added to the world population in $<12$ years, there is little agreement about the prospect for food supplies as this rate of increase continues. However, there appears to be general

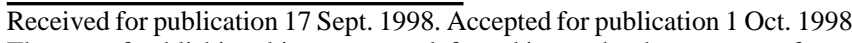
The cost of publishing this paper was defrayed in part by the payment of page charges. Under postal regulations, this paper therefore must be hereby marked advertisement solely to indicate this fact. agreement that when the population reached 5 billion in the late $1980 \mathrm{~s}$, nearly 1 billion or $20 \%$ were malnourished and starving. The percentage must be far higher in developing countries because the disparity between rich and poor countries has been increasing in recent years. Some who are optimistic about food supplies cite the increases brought about by the Green Revolution starting in the 1960s, but fail to note that the increases have slowed and not kept pace with recent population increases. World grain production, on which most people depend for their calories, peaked at $\approx 343 \mathrm{~kg}$ per person in 1984-86. In only one of the next 10 years did grain production approach that rate, and by 1994 and 1995 grain per person had fallen $>9 \%$. U.S. Dept. of Agriculture projections indicate that this decline will continue.

There is probably general agreement that the world's inadequate food supply is not being produced on a sustainable basis because of soil erosion, salinization, deforestation, silting of reservoirs, depletion of fossil fuels and ground water reserves, global warming, and pollution. Our children and grandchildren will be living in a stressful period when it will probably be determined whether the human species can adjust its numbers in a civilized way to the resources available on this planet. A second Green Revolution is needed to buy time for this adjustment.

Higher yields of modern grain varieties have been achieved largely by increasing the harvest index, the edible proportion of biomass, but this has probably reached its limit with a ton of straw supporting a ton of grain. The next logical step in increasing food production is to put more emphasis on crops with a higher harvest index, such as those whose vegetative parts are eaten. This has led in recent years to more research on starchy roots and tubers. Relatively little attention has been given to leafy vegetables and to crops, such as carrot, beet (Beta vulgaris L.), and Allium and Brassica species, whose edible parts represent a high proportion of total biomass. Many of these are minor crops not suited for transport or storage and consequently not reported in production statistics. Among them are crops with great potential for correcting some of the most important nutritional deficiencies in the tropics because: 1) there they can be grown almost continuously by or near the people who need them, thereby avoiding costs and losses in transportation, processing, and storage; 2) many of them combine high rates of edible calorie production with abundant micronutrients; 3 ) most have a far lower energy requirement for preparation than do grains or can be eaten raw, an advantage in situations where cooking fuel is scarcer than the food itself; and 4) many do not need to reach a definite stage of maturity but can be harvested as needed.

Munger (1987) presented calculations based on world average yields showing that carrots slightly exceeded maize (Zea mays L.), potatoes (Solanum tuberosum L.), and sweet potatoes [Ipomoea batatas (L.) Poir.] in production of edible calories per hectare per day. Onions and cabbage (Brassica oleracea L. Capitata Group) were a little lower and about the same as wheat (Triticum aestivum L.) and rice (Oryza sativa L.). Data are needed on other crops whose vegetative parts are eaten. To make valid comparisons of nutrient production, one needs information not only on harvested yield but on proportion of edible dry matter and on days from planting to harvest.

As a rough basis for making comparisons of nutritional productivity, we calculated in 1970 that high yields of rice and sugarcane in the Philippines were giving $\approx 35 \mathrm{~kg}$ of edible dry matter ha ${ }^{-1} \cdot \mathrm{d}^{-1}$. Yield data are available from a number of experiments with Amaranthus species harvested as leafy greens. Based on reasonable estimates of time and composition, these can produce $\approx 50 \%$ more edible dry matter ha $\mathrm{ha}^{-1} \cdot \mathrm{d}^{-1}$ than rice and considerably more protein, vitamins, and minerals.

Another promising leafy green vegetable is the broccoli-like form of chinese cabbage (Brassica rapa L. Pekinensis Group) known as "choi sum" or flowering white cabbage. Harvested $\approx 21 \mathrm{~d}$ from transplanting, all the aboveground biomass is edible and highly nutritious. Fragmentary yield data suggest a rate of edible dry-matter 
production equivalent to that of maize or potatoes.

A Philippine farmer (Roxas, 1996) provided unusually complete information about his experience with upland kangkong (Ipomoea aquatica L. Forsk). He harvested $100 \mathrm{~kg}$ from $\approx 100 \mathrm{~m}^{2} 25 \mathrm{~d}$ after sowing. Assuming composition similar to sweet potato vine tips, the edible dry-matter yield was $40 \mathrm{~kg} \cdot \mathrm{ha}^{-1} \cdot \mathrm{d}^{-1}$, at least as much as rice but containing more of other nutrients.

Thomas Bjorkman (personal communication) at the New York State Agricultural Experiment Station in Geneva, N.Y., studied table beets planted 20 July 1995 and harvested at $91 \mathrm{~d}$. These produced 42 $\mathrm{kg} \cdot \mathrm{ha}^{-1} \cdot \mathrm{d}^{-1}$ of edible dry matter, 26 in the roots and 16 in the edible leaves. Samples from commercial fields indicated that the rate would have been much higher had planting been earlier. This crop deserves more attention when one considers its high productivity, nutritive value of the leaves, and the edibility of the roots over a long period.

Many other crops for which we have little information might contribute to human health through their nutritional values. Modest investments in studying these could give big returns. These crops would not replace grains to meet calorie needs but rather supplement them as their supply becomes increasingly inadequate. We can do this with crops that are equally or more efficient in producing edible dry matter, while at the same time providing more protein, minerals, and vitamins, and all this at a lower cost in energy for production and preparation. This can be a second Green Revolution and one that is brought about by horticulturists.

\section{Literature Cited}

Gabelman, W.H. 1974. The prospects for genetic engineering to improve nutritional values, p. 147-155. In: P.L. White and N. Selvey (eds.). Nutritional qualities of fresh fruits and vegetables. Futura Publ. Co., Mt. Kisco, N.Y.

Munger, H.M. 1987. Adaptation and breeding of vegetable crops for improved human nutrition, p. 177-184. In: B. Quebedeaux and F.A. Bliss (eds.). Horticulture and human health. Proc. 1st Intl. Symp. on Hort. and Human Health. Prentice Hall, Englewood Cliffs, N.J.

Roxas, F. 1996. Rizal farmer earns instant money with seeded kangkong. Usapang Gulayan, by East-West Seed Co., Inc., Makati City, Philippines. $1(1): 1$.

Simon, P. 1995. Genetic variation and selection for carotene content in carrots. HortScience 30:706.

Stevens, M.A. 1974. Varietal influences on nutritional value, p. 87-110. In: P.L. White and N. Selvey (eds.). Nutritional qualities of fresh fruits and vegetables. Futura Publ. Co., Mt. Kisco, N.Y. 